\title{
MicroRNA-194 represses glioma cell epithelial-to-mesenchymal transition by targeting Bmi1
}

\author{
$\mathrm{XI} \mathrm{ZHANG}^{1^{*}}, \mathrm{CHUNYAN} \mathrm{WEI}^{2 *}, \mathrm{JIN} \mathrm{LI}^{1}, \mathrm{JIALI} \mathrm{LIU}^{3}$ and JIANQIANG QU ${ }^{1}$ \\ Departments of ${ }^{1}$ Neurosurgery, and ${ }^{2}$ Gynaecology and Obstetrics, ${ }^{3}$ Clinical Laboratory, \\ The Second Affiliated Hospital of Xi'an Jiaotong University, Xi'an, Shaanxi 710004, P.R. China
}

Received August 16, 2016; Accepted January 3, 2017

DOI: 10.3892/or.2017.5376

\begin{abstract}
MicroRNA-194 (miR-194) is frequently dysregulated in many types of cancer. However, the function of miR-194 in glioma remains unknown. In the present study, we aimed to investigate the biological functions of miR-194 in glioma and the potential molecular mechanism of miR-194 involved in glioma progression. We found that miR-194 expression was significantly reduced in glioma specimens and cell lines, as detected by real-time quantitative polymerase chain reaction (RT-qPCR) analysis. The overexpression of miR-194 inhibited while the suppression of miR-194 promoted cell migration, invasion and epithelial mesenchymal transition (EMT) in glioma cells. Bioinformatics analysis showed that the B cell-specific moloney murine leukemia virus insertion site 1 (Bmi1) was a direct target of miR-194, which was validated by Dual-Luciferase reporter assay, RT-qPCR and western blot analysis. The restoration of Bmil expression significantly abrogated the suppressive effect of miR-194 on glioma cell EMT. Taken together, the present study suggests that miR-194 inhibits glioma cell EMT by targeting Bmil providing novel insights into understanding the pathogenesis of glioma. The restoration of miR-194 may be a potential therapeutic strategy for glioma treatment.
\end{abstract}

Correspondence to: Dr Jianqiang Qu, Department of Neurosurgery, The Second Affiliated Hospital of Xi'an Jiaotong University, No. 157 West 5th Road, Xi'an, Shaanxi 710004, P.R. China

E-mail: qujianqiangxa@163.com

Abbreviations: Bmil, B cell-specific moloney murine leukemia virus insertion site; EMT, epithelial-to-mesenchymal transition; FBS, fetal bovine serum; miRNAs, microRNAs; RT-qPCR, realtime quantitative polymerase chain reaction; UTR, 3'-untranslated region

\section{*Contributed equally}

Key words: glioma, miR-194, Bmi1, epithelial-to-mesenchymal transition

\section{Introduction}

Glioma is one of the most prevalent brain tumors, with a high yearly mortality rate worldwide $(1,2)$. In spite of the current advances in cancer treatments, glioma is still an intractable disease due to the rapid growth, angiogenesis and metastasis of glioma cells $(3,4)$. The overall survival has not been significantly improved during the past decades $(4,5)$. Therefore, there is an urgent need to develop new therapies for glioma. However, the mechanism of glioma tumorigenesis is still not fully understood that hampers the development of new treatments for glioma.

In recent years, microRNAs (miRNAs), a group of small and non-coding RNA, have emerged as potential and promising tools for cancer diagnosis and treatments $(6,7)$. miRNAs can regulate target gene expression by interacting with the 3'-untranslated region (UTR) of the mRNA that inhibits translation or induces mRNA degradation $(8,9)$. Thus, miRNAs function as native regulators of gene expression. miRNAs are capable of modulating cancer cell proliferation, apoptosis, differentiation, migration and invasion by targeting oncogenes or tumor suppressors (10). There is increasing evidence suggesting that various miRNAs are dysregulated in glioma, which function as oncogenes or tumor suppressors $(11,12)$, highlighting their potential as novel agents for the treatment of glioma. However, the precise role of miRNAs in glioma remains largely unknown.

The B cell-specific moloney murine leukemia virus insertion site 1 (Bmil) is a self-renewal gene that is overexpressed in multiple human cancers (13). Bmil is a key component of the polycomb regulatory complex-1 regulating the transcription of a variety of important genes $(14,15)$. The inhibition of Bmil induces tumor cell apoptosis and increases susceptibility to chemotherapy and radiation therapy, indicating an oncogenic role of Bmil $(16,17)$. Bmil can induce cell transformation and promote cancer proliferation in vivo and in vitro through transcriptional repression of tumor suppressor genes including p16 ${ }^{\text {INK4A }}$ and p14 ${ }^{\text {ARF }}(18-20)$. The epithelial-to-mesenchymal transition (EMT) is an essential process for cancer invasion and metastasis (21). Notably, a recent study has shown that Bmil plays an important role in inducing EMT (22-24). Bmil plays an important role in glioma tumorigenesis through promoting the invasion, migration, angiogenesis and proliferation of glioma cells (25-28). Therefore, targeted therapy on 
Bmil may have promising and potential therapeutic values on glioma treatment.

Emerging evidence has suggested that miR-194 functions as a tumor suppressor in many types of human cancers including lung cancer (29), hepatocellular carcinoma (30) and colorectal cancer (31). However, the role of miR-194 in glioma remains unclear. In the present study, we aimed to explore the biological role of miR-194 and the underlying molecular mechanism in regulating glioma procession. We found that miR-194 expression was significantly decreased in glioma tissues and cell lines. Overexpression of miR-194 inhibited while the suppression of miR-194 promoted cell migration, invasion and EMT of glioma cells. Bioinformatic analysis indicated that Bmil was the direct target of miR-194 in glioma cells by which miR-194 regulated the glioma EMT process. Our findings provide a better understanding of the mechanism of glioma development and suggest that targeting Bmi1 by miR-194 may serve as an attractive treatment method for glioma.

\section{Materials and methods}

Tissue specimens and cell line. A total of 20 glioma specimens were histopathologically diagnosed at the Department of Neurosurgery, the Second Affiliated Hospital of Xi'an Jiaotong University (Xi'an, China). The specimens were resected prior to any therapeutic treatment. Normal brain tissues obtained from internal decompression patients undergoing surgical operation were used as a control. Prior written informed consent of the patients and approval were obtained from the Institutional Human Experiment and Ethic Committee of the Second Affiliated Hospital of Xi'an Jiaotong University. This study was performed in accordance with the Helsinki Declaration. U87, U251, SHG44 and A172 glioma cell lines and normal human astrocytes (NHA) were purchased from the Type Culture Collection of the Chinese Academy of Sciences (Shanghai, China). All cells were routinely cultured in Dulbecco's modified Eagle's medium (DMEM; Gibco, Rockville, MD, USA) containing $10 \%$ fetal bovine serum (FBS; Gibco) and 1\% penicillin/streptomycin mix (SigmaAldrich, St. Louis, MO, USA) in a humidified atmosphere containing $5 \% \mathrm{CO}_{2}$ at $37^{\circ} \mathrm{C}$.

Real-time quantitative polymerase chain reaction (RT-qPCR). Total RNA was isolated using TRIzol reagent (Invitrogen, Carlsbad, CA, USA) as per the manufacturer's instructions. For the analysis of Bmil expression, RNA was reverse-transcribed into cDNA by Moloney murine leukemia virus (M-MLV) reverse transcriptase (Takara Bio, Dalian, China). Glyceraldehyde 3-phosphate dehydrogenase (GAPDH) was used as an internal control for normalization. For the analysis of miR-194 expression, RNA was reverse-transcribed into cDNA by TaqMan MicroRNA reverse transcription kit (Applied Biosystems, Inc., Carlsbad, CA, USA). Small nuclear RNA U6 was used for normalization. The PCR amplification was performed by using the SYBR-Green Master Mix kit (Bio-Rad Laboratories, Hercules, CA, USA) on an Applied Biosystems AB 7500 real-time PCR system (Applied Biosystems). The primers used were as follows: miR-194, forward, 5'-atggacctggggccacgaag-3' and reverse, 5'-tctggcct gggagcgtcg-3'; U6, forward, 5'-cgcttcggcagcacatatactaa-3' and reverse, 5'-tatggaacgcttcacgaatttgc-3'; Bmi1, forward, 5'-atgca tcgaacaacgagaatcaagatcact-3' and reverse, 5'-tcaaccagaagaa gttgctgatgaccc-3'; and GAPDH, forward, 5'-ccatgttcgtcatggtg tg-3' and reverse, 5'-ggtgctaagcagttggtggtg-3'. Gene expression was calculated using the $2^{-\Delta \Delta C t}$ method, normalized against U6 or GAPDH and then compared with the control group.

Oligonucleotides, plasmids and transfection. miR-194 mimics, miR-194 inhibitor and their negative controls were purchased from Shanghai GenePharma, Co., Ltd. (Shanghai, China). The open reading frame of Bmil was inserted into the pcDNA3.0 vector (Invitrogen). All the transfections were performed using Lipofectamine 2000 (Invitrogen) according to the manufacturer's instructions.

Migration and invasion assay. For cell migration, $1 \times 10^{5}$ cells transfected with miR-194 mimics or miR-194 inhibitors were placed in the upper chambers of a Transwell (Costar, Cambridge, MA, USA) with serum-free medium and the lower chambers were filled with medium containing $10 \%$ FBS. For cell invasion, the upper chambers were coated with Matrigel (BD Biosciences, San Jose, CA, USA). After being cultured for $24 \mathrm{~h}$ at $37^{\circ} \mathrm{C}$, the non-migrated or non-invaded cells on the top of the well were gently removed and the cells on the lower surface of the membrane were fixed with $70 \%$ ethanol and stained with $0.1 \%$ violet (Sigma-Aldrich). The cells were observed and counted under a microscope (Olympus Corp., Tokyo, Japan).

Western blot analysis. Proteins were extracted by cell lysis buffer and the protein concentration was detected by a BCA kit (Beyotime Institute of Biotechnology, Haimen, China). A total of $50 \mu \mathrm{g}$ protein was separated by SDS-PAGE and electrotransferred to a polyvinylidene fluoride membrane (Bio-Rad Laboratories). The membrane was blocked by $5 \%$ non-fat milk and then incubated with primary antibodies at $4^{\circ} \mathrm{C}$ overnight. The membrane was then incubated with horseradish peroxidase-conjugated secondary antibodies (Bosis, Beijing, China) for $1 \mathrm{~h}$ at $37^{\circ} \mathrm{C}$. Ultimately, the membrane was detected by an ECL western blotting kit (Pierce, Rockford, IL, USA) according to the manufacturer's instructions. The image was analyzed by Image-Pro Plus 6.0 software (Media Cybernetics, Inc., Rockville, MD, USA). The values were normalized against GAPDH and then were compared with the control group. Primary antibodies used in this experiment including anti-E-cadherin, anti-vimentin, anti-Bmil and anti-GAPDH were purchased from Santa Cruz Biotechnology (Santa Cruz, CA, USA).

Dual-Luciferase reporter assay. The Bmi1 3'-UTR harboring the seed-matched sequences of miR-194 with or without mutation was inserted into pmirGLO Dual-Luciferase vector (Promega Corp., Madison, WI, USA). Glioma cells were seeded into 24-well plates and co-transfected with miR-194 mimics or miR-194 inhibitor and the constructed wild-type or mutant pmirGLO-Bmil 3'-UTR into glioma cells using Lipofectamine 2000. After $48 \mathrm{~h}$, the luciferase activity was analyzed by a Dual-luciferase reporter assay system kit (Promega). 

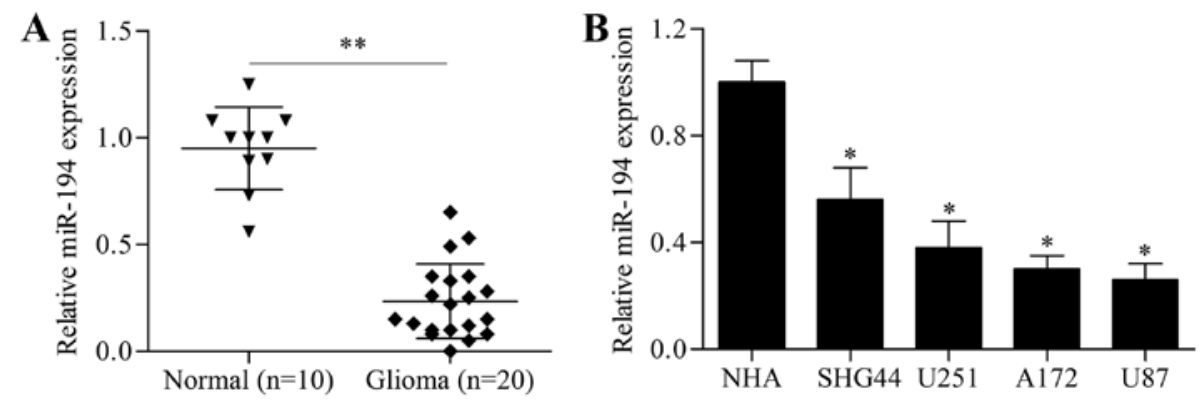

Figure 1. The expression of miR-194 in glioma tissues and cell lines. (A) Relative miR-194 expression in glioma tissues and normal brain tissues was examined by RT-PCR. ${ }^{* *} \mathrm{P}<0.01$ vs. normal. (B) RT-qPCR analysis of miR-194 in glioma cell lines (U251, SHG44, A172 and U87) and normal human astrocytes (NHA). "P $<0.05$ vs. NHA.

A

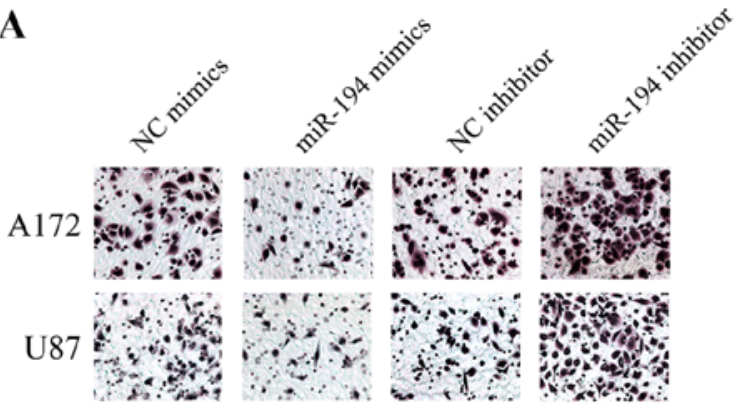

C

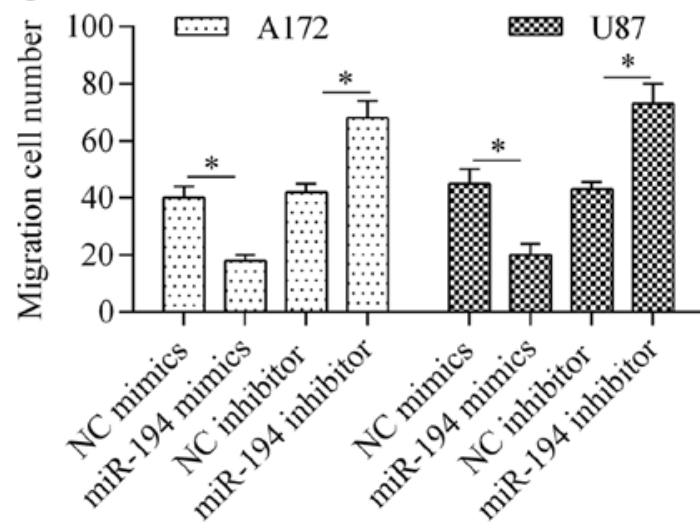

B

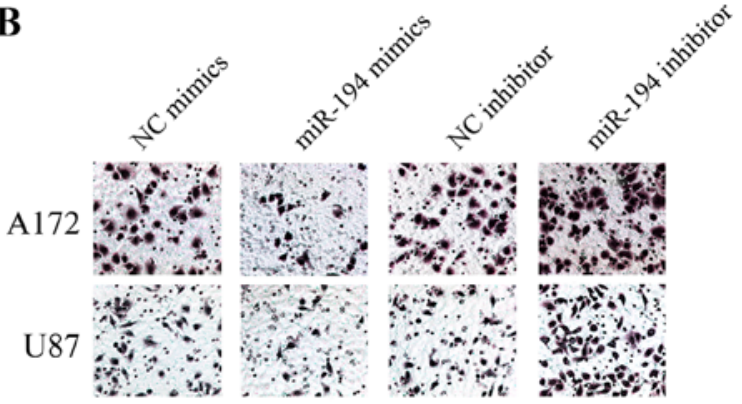

D

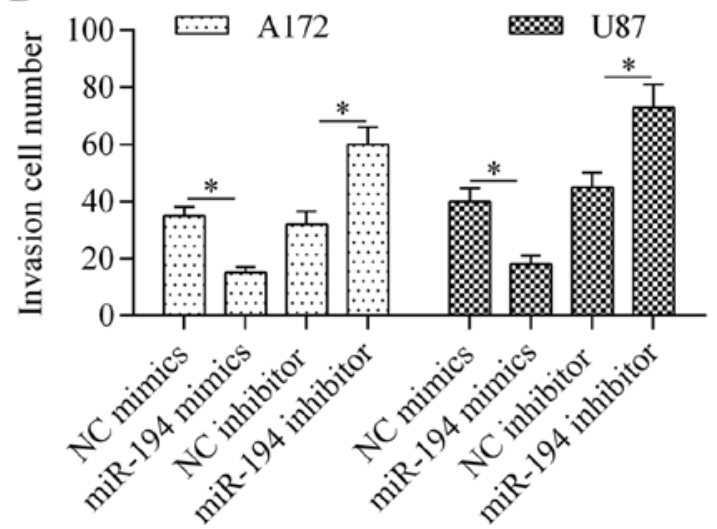

Figure 2. miR-194 represses glioma cell migration and invasion. A172 and U87 cells were transiently transfected with miR-194 mimics or miR-194 inhibitors. (A) Glioma cell migration and (B) invasion were detected by Transwell assay. (C) Quantitative cell number of migrated cells. (D) Quantitative cell number of invaded cells. ${ }^{*} \mathrm{P}<0.05$.

Data analysis. Data are reported as means \pm standard deviation (SD). Statistical analyses were performed using SPSS version 11.5 software (SPSS, Inc., Chicago, IL, USA). Differences were calculated by the Student's t-test or one-way analysis of variance (ANOVA) followed by Bonferroni post hoc. When the P-value was $<0.05$, the difference was considered to be statistically significant.

\section{Results}

miR-194 is frequently lower in glioma tissues and cell lines. To determine whether miR-194 is involved in glioma development, we first analyzed the expression patterns of miR-194 in glioma specimens by RT-qPCR. The results showed that miR-194 was frequently downregulated in glioma tissues compared with normal brain tissue (Fig. 1A). Moreover, the expression levels of miR-194 were also decreased in the four glioma cell lines examined, particularly in A172 and U87, when compared with normal human astrocytes (Fig. 1B). These results indicate that miR-194 may play an important role in glioma.

miR-194 suppresses glioma cell migration and invasion. To investigate the biological role of miR-194 in glioma, we performed gain- and loss-of-function experiments by transiently transfecting miR-194 mimics or miR-194 inhibitors in A172 and U87 cells. We then detected the functional effect of miR-194 on glioma cell migration and invasion by Transwell assay. The results showed that miR-194 overexpression significantly inhibited glioma cell migration (Fig. 2A and C) and invasion (Fig. 2B and D) in A172 and U87 cells. Conversely, 
A

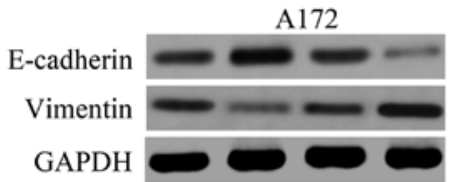

B

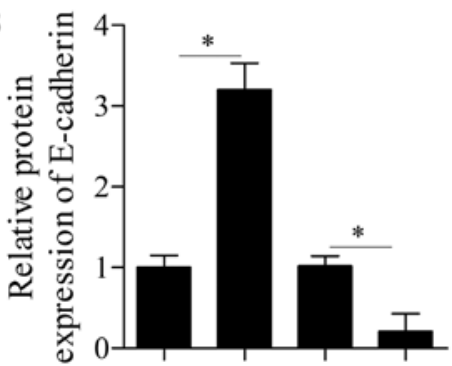

C

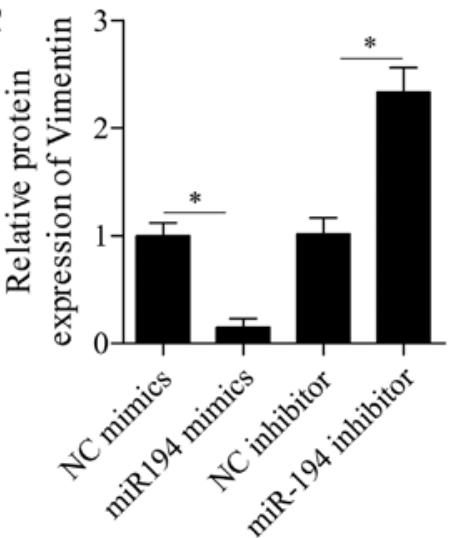

D

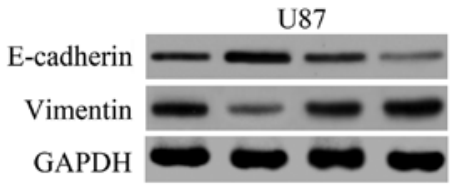

$\mathbf{E}$

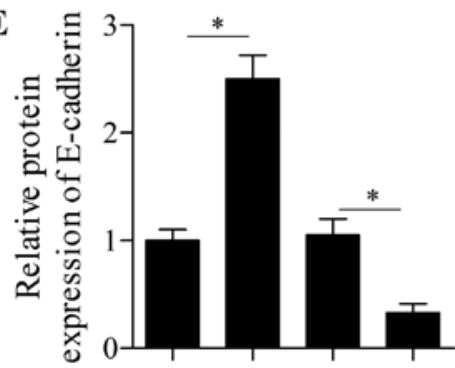

F

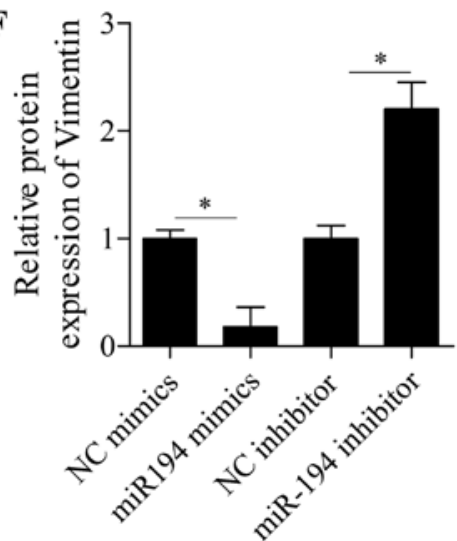

Figure 3. miR-194 inhibits glioma cell EMT. The effect of miR-194 overexpression or suppression on E-cadherin and vimentin was detected by western blot analysis in A172 (A-C) and U87 (D-F) cells. The relative expression of proteins was quantified by Image-Pro Plus 6.0 software. "P<0.05.

A 3'-agGUGUACCUCAACGACAAUGu-5' hsa-miR-194 5'-uUUACAUAUA--UUGCUGUUACu-3, Bmil (WT)
1 1

5'-unUACAUAUA--UAGGUCUGAUu-3' Bmil (MT)
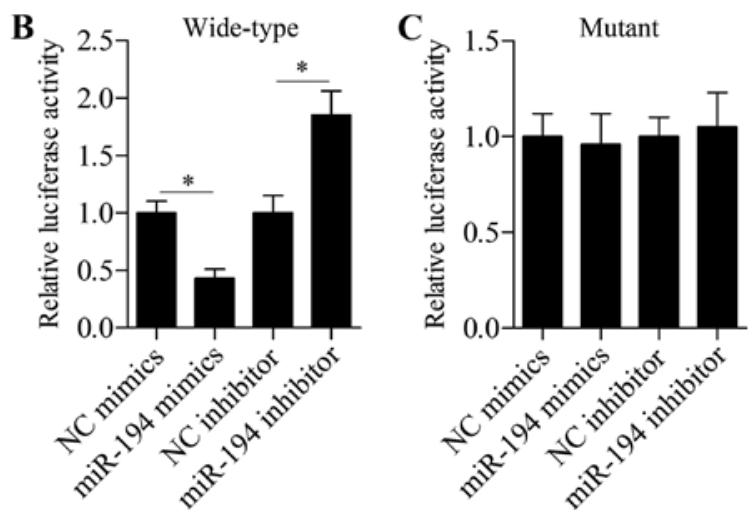

Figure 4. miR-194 targets the 3'-UTR of Bmil. (A) Schematic representation of the seed region between miR-194 and Bmil 3'-UTR. (B and C) DualLuciferase report assay. U87 cells were co-transfected with the miR-194 mimics or miR-194 inhibitors and report vectors containing wild-type (WT) or mutant (MT) Bmil 3'-UTR. After $48 \mathrm{~h}$, the luciferase activity was analyzed by a dual-luciferase reporter assay system kit. ${ }^{*} \mathrm{P}<0.05$.

miR-194 suppression markedly increased glioma cell migration (Fig. 2A and C) and invasion (Fig. 2B and D). These data imply a suppressive role of miR-194 on glioma metastasis.
miR-194 suppresses EMT of glioma cells. To further investigate the contribution of miR-194 on glioma metastasis, we examined the biological role of miR-194 in regulating glioma cell EMT. Western blot analysis showed that the expression of epithelial marker E-cadherin was significantly increased, whereas expression of the mesenchymal marker vimentin was markedly decreased by miR-194 overexpression in A172 cells (Fig. 3A-C). In contrast, miR-194 suppression showed the opposite effects (Fig. 3A-C). Similar results were also observed in U87 cells (Fig. 3D-F), suggesting a suppressive role of miR-194 in glioma cell EMT.

miR-194 directly targets Bmil. To investigate the underlying molecular mechanism by which miR-194 regulates glioma cell EMT, we used bioinformatic analysis to identify the potential target of miR-194. Among these predicted target genes, Bmi1, an important regulator for cancer metastasis (22-24), caught our attention. The predicted binding site between miR-194 and Bmil 3'-UTR is illustrated in Fig. 4A. To verify that Bim1 is a direct target gene of miR-194, we performed a Dual-Luciferase reporter assay. The 3'-UTR fragments of Bmil, which contain a wild-type or mutant binding site of miR-194, were cloned into the luciferase reporter vector. Overexpression of miR-194 significantly restrained the luciferase activity in U87 cells transfected with luciferase reporter vector containing wildtype Bmi1 3'-UTR, whereas miR-194 suppression promoted the luciferase activity (Fig. 4B). However, neither miR-194 
A

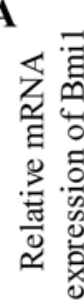

C
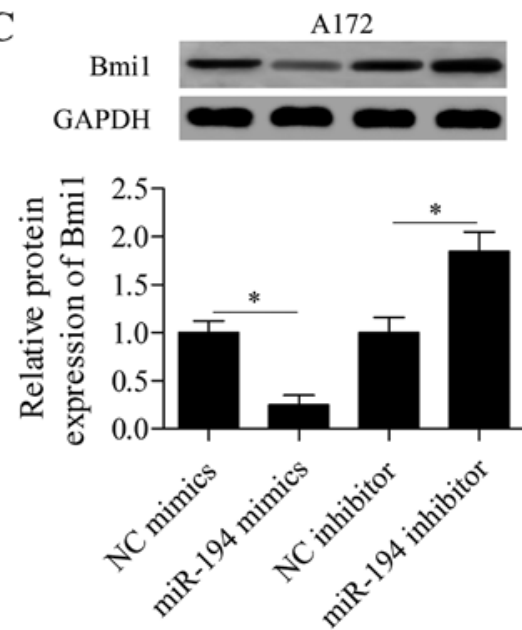

B

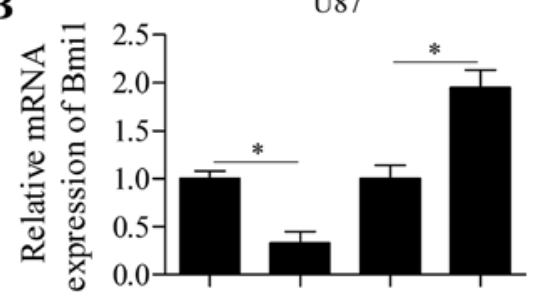

D
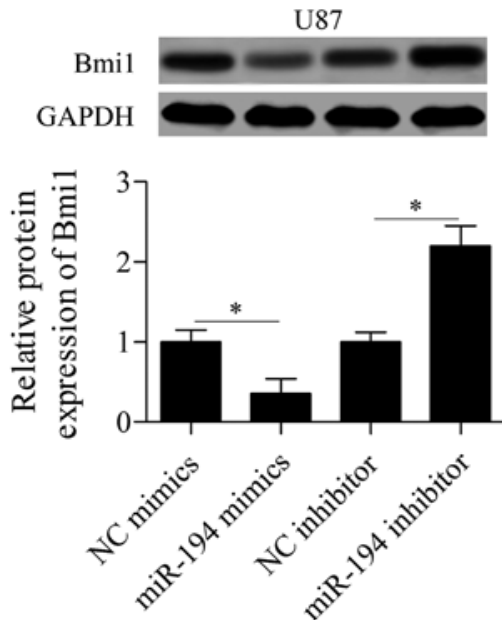

Figure 5. miR-194 regulates Bmil expression. A172 and U87 cells were transfected with miR-194 mimics or miR-194 inhibitors for $48 \mathrm{~h}$. The mRNA expression of Bmil in (A) A172 and (B) U87 cells was detected by RT-qPCR analysis. The protein expression of Bmi1 in (C) A172 and (D) U87 cells was detected by western blot analysis. The relative expression of proteins was quantified by Image-Pro Plus 6.0 software. ${ }^{*} \mathrm{P}<0.05$.

overexpression nor suppression showed an obvious effect on luciferase activity of the luciferase reporter vector containing a mutant 3'-UTR (Fig. 4C). Next, we further determined the direct effect of miR-194 on regulating Bmil expression. RT-qPCR analysis showed that the mRNA expression of Bmil was significantly decreased or increased by miR-194 overexpression or suppression, respectively (Fig. 5A and B). Consistently, western blot analysis identified that Bmil protein expression was regulated by miR-194 (Fig. 5C and D). Taken together, these results suggest that miR-194 regulates Bmi1 expression by directly targeting the 3'-UTR of Bmi1.

miR-194 inhibits glioma EMT through downregulating Bmil. To verify whether the tumor suppressor role of miR-194 in glioma is mediated by suppressing the expression of Bmil, we performed a rescue assay. Glioma cells were co-transfected with miR-194 mimics and Bmil-overexpressing vector. The decreased protein expression of Bmil induced by miR-194 overexpression was significantly restored by transfection with a Bmil-overexpressing vector (Fig. 6A and E). As expected, the inhibitory role of miR-194 on glioma EMT was rescued by Bmil overexpression (Fig. 6A-H). These results suggest that the suppressive role of miR-194 on glioma EMT is mediated by inhibiting Bmil.

\section{Discussion}

It has now been clearly established that miRNAs play an important role in regulating the tumorigenesis and metastasis of glioma (32-34). Therefore, the identification of glioma-associated miRNAs as biomarkers for glioma diagnosis, prognosis and treatment is of great importance. In the present study, we found that miR-194 was a novel glioma-associated miRNA that was decreased in glioma specimens and cell lines. The functional experiments indicated that miR-194 inhibited glioma cell migration, invasion and EMT, possibly through targeting and regulating Bmil. Collectively, our data suggest that miR-194 plays an important role in glioma procession, indicating a novel therapeutic target for glioma.

Growing evidence has demonstrated that miR-194 is a tumor-associated miRNA that is frequently dysregulated in many types of human cancers. miR-194 expression was markedly decreased in hepatocellular carcinoma and miR-194 overexpression inhibited cell proliferation by targeting mitogen-activated protein kinase 4 (30). Other studies reported that miR-194 was frequently downregulated in colorectal cancer $(35,36)$. miR-194 can inhibit colorectal carcinogenesis by targeting mitogen-activated protein kinase 4 (37) or Akt2 (31). Several studies have reported that miR-194 represses the progression and metastasis of non-small lung cancer through targeting bone morphogenetic protein 1 and p2 $7^{\mathrm{kip} 1}$ (38), forkhead box A1 protein (39) and human nuclear distribution protein C (29). miR-194 can suppress gastric cancer cell proliferation and EMT through targeting RING box protein 1 (40) and forkhead box protein M1 (41). The tumor suppressive role of miR-194 is also observed in oral squamous cell carcinoma (42), bladder cancer (43) and clear cell renal cell carcinoma (44). However, the role of miR-194 in glioma remains unknown. In line with these findings, this study demonstrated that miR-194 functioned as a tumor suppressor in glioma. We found that miR-194 was decreased in glioma tissues and cell lines. Overexpression of miR-194 
A

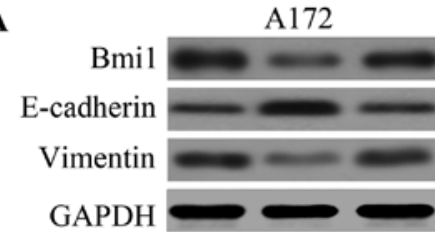

B

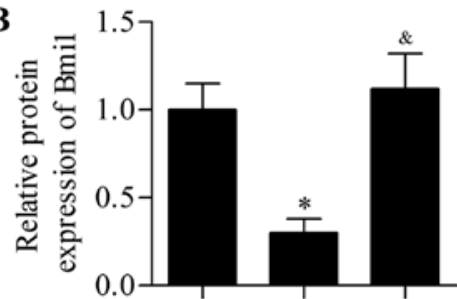

C

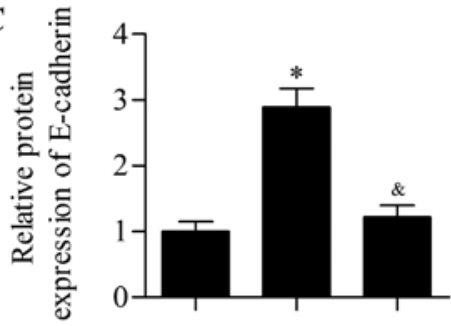

D

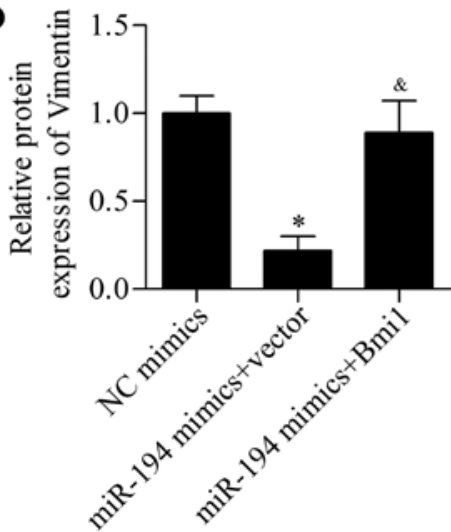

E

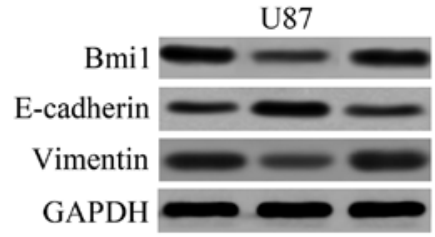

$\mathbf{F}$

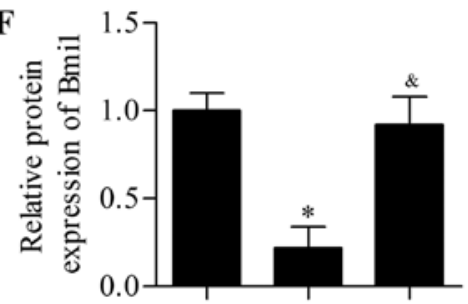

G

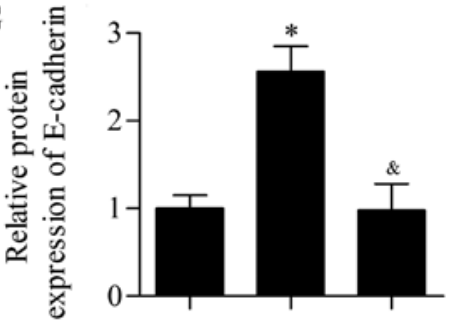

$\mathbf{H}$

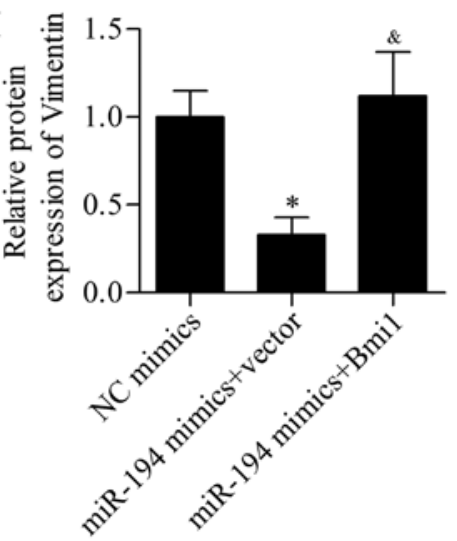

Figure 6. miR-194 functions a tumor suppressor through Bmi1. Cells were co-transfected with miR-194 mimics and pcDNA-Bmi1 vector encoding the fulllength coding sequence without the 3'-UTR region. The expression levels of Bmil, E-cadherin and vimentin in (A-D) A172 and (E-H) U87 cells were detected by western blot analysis. The relative expression of proteins was quantified by Image-Pro Plus 6.0 software. ${ }^{*} \mathrm{P}<0.05$ vs. NC mimics; ${ }^{\circledR} \mathrm{P}<0.05 \mathrm{vs}$. miR-194 mimics+vector.

inhibited glioma cell migration, invasion and EMT through inhibiting Bmil. However, an oncogenic role of miR-194 is observed in pancreatic ductal adenocarcinoma that promotes tumor growth and progression through inhibiting the tumor suppressor DACH1 (45). Therefore, the precise role of miR-194 in cancer progression requires further investigation.

Bmil has been suggested as an oncogene that is frequently elevated in various cancer types and is correlated with a worse prognosis (13). Bmil has been reported to inhibit tumor suppressor genes including $\mathrm{p} 14^{\mathrm{ARF}}$, p16 ${ }^{\mathrm{INK} 4 \mathrm{a}}, \mathrm{KIF} 1 \mathrm{~B} \beta$ and TSLC1 (46). Bmil is a critical regulator for EMT and cancer metastasis (47). Knockdown of Bmil abolishes the ionizing irradiation-induced EMT of breast cancer cells (48). Twist1 and Bmi-1 can act cooperatively to inhibit E-cadherin and $\mathrm{p} 16^{\mathrm{INK} 4 \mathrm{a}}$, leading to EMT induction (49). Bmil plays an important role in development of the central nervous system; however, the dysregulation of Bmil contributes to the development of brain tumors $(50,51)$. Overexpression of Bmi1 was found in human medulloblastomas, correlated with activation of the sonic hedgehog pathway (50). Bmil is highly elevated in glioma tissues and patients with high levels of Bmil show a poor survival rate (52). Bmil promotes glioma cell migration and invasion via nuclear factor kappa B and p16 $(25,28,53)$. Consistently, our results showed that the inhibition of Bmil by miR-194 significantly suppressed the glioma cell migration, invasion and EMT, further implying that Bmil can serve as a therapeutic target for preventing glioma metastasis.

In the present study, we demonstrated that miR-194 functions as an EMT regulator in glioma via targeting Bmil. We showed that miR-194 could directly target the 3'-UTR of Bmil and inhibit Bmil expression. Our findings are consistent with a previous study which revealed that miR-194 suppresses the EMT of endometrial cancer cells by targeting Bmil (54). The present study further confirms that Bmil is a functional target of miR-194. A recent study (55) suggested that targeting Bmil by miRNAs is a promising strategy for cancer prevention. 
Deng et al (55) reported that miR-376c suppresses cervical cancer cell proliferation and invasion by targeting Bmil. miR-494-3p enhances the radiosensitivity of oral squamous carcinoma cells through targeting Bmil (56). miR-452 and miR-403 can inhibit the metastasis of non-small cell lung cancer through inhibiting Bmil $(57,58)$. miR-218, functioning as a negative regulator of Bmil, is also found in bladder cancer (59) and esophageal squamous cell carcinoma (60). Besides these miRNAs, miR-429, miR-200c, mIR-221 and miR-320a have been demonstrated to directly target Bmil in various cancer cells $(22,61-63)$. These studies indicate that Bim1 undergoes epigenetic regulation by various miRNAs that may contribute to the development of cancer. A better understanding of Bmil by miRNAs will provide a new insight into understanding glioma pathogenesis.

EMT is considered as major modulator of metastasis formation in epithelial solid tumors, and the EMT of glioma has also been widely studied (64). Twist1, ZEB1/ZEB2 and SNAI1/SNAI2 have been suggested as the major regulators for EMT in glioma (65-67). Various miRNAs such as miR-200b, miR-590-3p and miR-181c are reported to be involved in regulating EMT of glioma (68-70). Our present study showed for the first time that miR-194 was decreased in glioma which could inhibit glioma cell migration, invasion and EMT. Importantly, we found that Bmil was a direct target of miR-194 in glioma cells by which miR-194 inhibited glioma cell EMT. miR-194 may serve as a novel biomarker as well as a therapeutic target in glioma. However, further in vivo studies are required to fully elucidate the exact role and molecular mechanism of miR-194 in the regulation of glioma.

\section{Acknowledgements}

The present study was supported by the Social Research and Development Program of Shaanxi Province (no. 2016SF-110).

\section{References}

1. Westphal M and Lamszus K: The neurobiology of gliomas: From cell biology to the development of therapeutic approaches. Nat Rev Neurosci 12: 495-508, 2011.

2. Siegel RL, Miller KD and Jemal A: Cancer statistics, 2016. CA Cancer J Clin 66: 7-30, 2016.

3. Furnari FB, Fenton T, Bachoo RM, Mukasa A, Stommel JM, Stegh A, Hahn WC, Ligon KL, Louis DN, Brennan C, et al: Malignant astrocytic glioma: Genetics, biology, and paths to treatment. Genes Dev 21: 2683-2710, 2007.

4. Pollack IF: Neuro-oncology: Therapeutic benefits of reirradiation for recurrent brain tumors. Nat Rev Neurol 6: 533-535, 2010

5. Khasraw M and Lassman AB: Neuro-oncology: Late neurocognitive decline after radiotherapy for low-grade glioma. Nat Rev Neurol 5: 646-647, 2009.

6. Pang JC, Kwok WK, Chen Z and Ng HK: Oncogenic role of microRNAs in brain tumors. Acta Neuropathol 117: 599-611, 2009.

7. Silber J, James CD and Hodgson JG: microRNAs in gliomas: Small regulators of a big problem. Neuromolecular Med 11: 208-222, 2009.

8. Bartel DP: MicroRNAs: Genomics, biogenesis, mechanism, and function. Cell 116: 281-297, 2004.

9. Winter J, Jung S, Keller S, Gregory RI and Diederichs S: Many roads to maturity: microRNA biogenesis pathways and their regulation. Nat Cell Biol 11: 228-234, 2009.

10. Manikandan J, Aarthi JJ, Kumar SD and Pushparaj PN: Oncomirs: The potential role of non-coding microRNAs in understanding cancer. Bioinformation 2: 330-334, 2008.
11. Zhang Y, Dutta A and Abounader R: The role of microRNAs in glioma initiation and progression. Front Biosci (Landmark Ed) 17: 700-712, 2012.

12. Besse A, Sana J, Fadrus P and Slaby O: MicroRNAs involved in chemo- and radioresistance of high-grade gliomas. Tumour Biol 34: 1969-1978, 2013.

13. Cao L, Bombard J, Cintron K, Sheedy J, Weetall ML and Davis TW: BMI1 as a novel target for drug discovery in cancer. J Cell Biochem 112: 2729-2741, 2011.

14. Guney I, Wu S and Sedivy JM: Reduced c-Myc signaling triggers telomere-independent senescence by regulating Bmi-1 and p16 ${ }^{\text {INK4a }}$. Proc Natl Acad Sci USA 103: 3645-3650, 2006.

15. Silva J, García JM, Peña C, García V, Domínguez G, Suárez D, Camacho FI, Espinosa R, Provencio M, España P, et al: Implication of polycomb members Bmi-1, Mel-18, and Hpc-2 in the regulation of p16INK4a, p14ARF, h-TERT, and c-Myc expression in primary breast carcinomas. Clin Cancer Res 12: 6929-6936, 2006.

16. Wu J, Hu D, Yang G, Zhou J, Yang C, Gao Y and Zhu Z: Down-regulation of BMI-1 cooperates with artemisinin on growth inhibition of nasopharyngeal carcinoma cells. J Cell Biochem 112: 1938-1948, 2011.

17. Wu Z, Min L, Chen D, Hao D, Duan Y, Qiu G and Wang Y: Overexpression of BMI-1 promotes cell growth and resistance to cisplatin treatment in osteosarcoma. PLoS One 6: e14648, 2011.

18. Jacobs JJ, Scheijen B, Voncken JW, Kieboom K, Berns A and van Lohuizen M: Bmi-1 collaborates with c-Myc in tumorigenesis by inhibiting c-Myc-induced apoptosis via INK4a/ARF. Genes Dev 13: 2678-2690, 1999.

19. Jiang L, Li J and Song L: Bmi-1, stem cells and cancer. Acta Biochim Biophys Sin (Shanghai) 41: 527-534, 2009.

20. Itahana K, Zou Y, Itahana Y, Martinez JL, Beausejour C, Jacobs JJ, Van Lohuizen M, Band V, Campisi J and Dimri GP: Control of the replicative life span of human fibroblasts by p16 and the polycomb protein Bmi-1. Mol Cell Biol 23: 389-401, 2003.

21. Kalluri R and Weinberg RA: The basics of epithelial-mesenchymal transition. J Clin Invest 119: 1420-1428, 2009.

22. Qiu M, Liang Z, Chen L, Tan G, Wang K, Liu L, Liu J and Chen H: MicroRNA-429 suppresses cell proliferation, epithelialmesenchymal transition, and metastasis by direct targeting of BMI1 and E2F3 in renal cell carcinoma. Urol Oncol 33: 332. e9-18, 2015

23. Wei XL, Dou XW, Bai JW, Luo XR, Qiu SQ, Xi DD, Huang WH, Du CW, Man K and Zhang GJ: ER $\alpha$ inhibits epithelialmesenchymal transition by suppressing Bmil in breast cancer. Oncotarget 6: 21704-21717, 2015.

24. Paranjape AN, Balaji SA, Mandal T, Krushik EV, Nagaraj P, Mukherjee $\mathrm{G}$ and Rangarajan A: Bmil regulates self-renewal and epithelial to mesenchymal transition in breast cancer cells through Nanog. BMC Cancer 14: 785, 2014.

25. Liang J, Wang P, Xie S, Wang W, Zhou X, Hu J, Shi Q, Zhang X and Yu R: Bmi-1 regulates the migration and invasion of glioma cells through p16. Cell Biol Int 39: 283-290, 2015.

26. Tu Y, Gao X, Li G, Fu H, Cui D, Liu H, Jin W and Zhang Y: MicroRNA-218 inhibits glioma invasion, migration, proliferation, and cancer stem-like cell self-renewal by targeting the polycomb group gene Bmi1. Cancer Res 73: 6046-6055, 2013.

27. Jiang L, Song L, Wu J, Yang Y, Zhu X, Hu B, Cheng SY and Li M: Bmi-1 promotes glioma angiogenesis by activating NF- $\mathrm{B}$ signaling. PLoS One 8: e55527, 2013.

28. Jiang L, Wu J, Yang Y, Liu L, Song L, Li J and Li M: Bmi-1 promotes the aggressiveness of glioma via activating the NF-kappaB/MMP-9 signaling pathway. BMC Cancer 12: 406, 2012.

29. Zhou L, Di Q, Sun B, Wang X, Li M and Shi J: MicroRNA-194 restrains the cell progression of non-small cell lung cancer by targeting human nuclear distribution protein C. Oncol Rep 35: 3435-3444, 2016

30. Zhao Y,Li F, Zhang X, Liu A, Qi J, Cui H and Zhao P: MicroRNA194 acts as a prognostic marker and inhibits proliferation in hepatocellular carcinoma by targeting MAP4K4. Int J Clin Exp Pathol 8: 12446-12454, 2015.

31. Zhao HJ, Ren LL, Wang ZH, Sun TT, Yu YN, Wang YC, Yan TT, Zou W, He J, Zhang Y, et al: MiR-194 deregulation contributes to colorectal carcinogenesis via targeting AKT2 pathway. Theranostics 4: 1193-1208, 2014.

32. Kwak PB, Iwasaki S and Tomari Y: The microRNA pathway and cancer. Cancer Sci 101: 2309-2315, 2010. 
33. Karsy M, Arslan E and Moy F: Current progress on understanding MicroRNAs in glioblastoma multiforme. Genes Cancer 3: 3-15, 2012.

34. Tivnan A and McDonald KL: Current progress for the use of miRNAs in glioblastoma treatment. Mol Neurobiol 48: 757-768, 2013.

35. Chiang Y, Song Y, Wang Z, Liu Z, Gao P, Liang J, Zhu J, Xing C and $\mathrm{Xu} \mathrm{H}$ : microRNA-192, -194 and -215 are frequently downregulated in colorectal cancer. Exp Ther Med 3: 560-566, 2012.

36. Basati G, Razavi AE, Pakzad I and Malayeri FA: Circulating levels of the miRNAs, miR-194, and miR-29b, as clinically useful biomarkers for colorectal cancer. Tumour Biol 37: 1781-1788, 2016.

37. Wang B, Shen ZL, Gao ZD, Zhao G, Wang CY, Yang Y, Zhang JZ, Yan YC, Shen C, Jiang KW, et al: MiR-194, commonly repressed in colorectal cancer, suppresses tumor growth by regulating the MAP4K4/c-Jun/MDM2 signaling pathway. Cell Cycle 14: 1046-1058, 2015.

38. Wu X, Liu T, Fang O, Leach LJ, Hu X and Luo Z: miR-194 suppresses metastasis of non-small cell lung cancer through regulating expression of BMP1 and $27^{\mathrm{kipl}}$. Oncogene 33 : 1506-1514, 2014

39. Zhu X, Li D, Yu F, Jia C, Xie J, Ma Y, Fan S, Cai H, Luo Q, Lv Z, et al: miR-194 inhibits the proliferation, invasion, migration, and enhances the chemosensitivity of non-small cell lung cancer cells by targeting forkhead box A1 protein. Oncotarget 7: 13139-13152, 2016.

40. Chen X, Wang Y, Zang W, Du Y, Li M and Zhao G: miR-194 targets RBX1 gene to modulate proliferation and migration of gastric cancer cells. Tumour Biol 36: 2393-2401, 2015.

41. Li Z, Ying X, Chen H, Ye P, Shen Y, Pan W and Zhang L: MicroRNA-194 inhibits the epithelial-mesenchymal transition in gastric cancer cells by targeting FoxM1. Dig Dis Sci 59: 2145-2152, 2014

42. Chi H: miR-194 regulated AGK and inhibited cell proliferation of oral squamous cell carcinoma by reducing PI3K-Akt-FoxO3a signaling. Biomed Pharmacother 71: 53-57, 2015.

43. Zhang M, Zhuang Q and Cui L: MiR-194 inhibits cell proliferation and invasion via repression of RAP2B in bladder cancer. Biomed Pharmacother 80: 268-275, 2016

44. Nofech-Mozes R, Khella HW, Scorilas A, Youssef L, Krylov SN, Lianidou E, Sidiropoulos KG, Gabril M, Evans A and Yousef GM: MicroRNA-194 is a marker for good prognosis in clear cell renal cell carcinoma. Cancer Med 5: 656-664, 2016.

45. Zhang J, Zhao CY, Zhang SH, Yu DH, Chen Y, Liu QH, Shi M, Ni CR and Zhu MH: Upregulation of miR-194 contributes to tumor growth and progression in pancreatic ductal adenocarcinoma. Oncol Rep 31: 1157-1164, 2014

46. Kamijo T: Role of stemness-related molecules in neuroblastoma. Pediatr Res 71: 511-515, 2012.

47. Ren H, Du P, Ge Z, Jin Y, Ding D, Liu X and Zou Q: TWIST1 and BMI1 in cancer metastasis and chemoresistance. J Cancer 7: 1074-1080, 2016

48. Yuan W, Yuan Y, Zhang T and Wu S: Role of Bmi-1 in regulation of ionizing irradiation-induced epithelial-mesenchymal transition and migration of breast cancer cells. PLoS One 10: e0118799, 2015.

49. Yang MH, Hsu DS, Wang HW, Wang HJ, Lan HY, Yang WH, Huang CH, Kao SY, Tzeng CH, Tai SK, et al: Bmil is essential in Twist1-induced epithelial-mesenchymal transition. Nat Cell Biol 12: 982-992, 2010.

50. Leung C,Lingbeek M, Shakhova O,Liu J, Tanger E, Saremaslani $P$, Van Lohuizen M and Marino S: Bmil is essential for cerebellar development and is overexpressed in human medulloblastomas. Nature 428: 337-341, 2004

51. Molofsky AV, Pardal R, Iwashita T, Park IK, Clarke MF and Morrison SJ: Bmi-1 dependence distinguishes neural stem cell self-renewal from progenitor proliferation. Nature 425: 962-967, 2003.

52. Wu Z, Wang Q, Wang L, Li G, Liu H, Fan F, Li Z, Li Y and Tu Y: Combined aberrant expression of $\mathrm{Bmi1}$ and $\mathrm{EZH} 2$ is predictive of poor prognosis in glioma patients. J Neurol Sci 335: 191-196, 2013.
53. Sun $\mathrm{P}, \mathrm{Mu} \mathrm{Y}$ and $\mathrm{Zhang} \mathrm{S}$ : A novel $\mathrm{NF}-\kappa \mathrm{B} / \mathrm{MMP}-3$ signal pathway involves in the aggressivity of glioma promoted by Bmi-1. Tumour Biol 35: 12721-12727, 2014.

54. Dong P, Kaneuchi M, Watari H, Hamada J, Sudo S, Ju J and Sakuragi N: MicroRNA-194 inhibits epithelial to mesenchymal transition of endometrial cancer cells by targeting oncogene BMI-1. Mol Cancer 10: 99, 2011.

55. Deng Y, Xiong Y and Liu Y: miR-376c inhibits cervical cancer cell proliferation and invasion by targeting BMI1. Int J Exp Pathol 97: 257-265, 2016.

56. Weng JH, Yu CC, Lee YC, Lin CW, Chang WW and Kuo YL: miR-494-3p induces cellular senescence and enhances radiosensitivity in human oral squamous carcinoma cells. Int $\mathbf{J}$ Mol Sci 17: 17, 2016.

57. He Z, Xia Y, Pan C, Ma T, Liu B, Wang J, Chen L and Chen Y: Up-regulation of miR-452 inhibits metastasis of non-small cell lung cancer by regulating BMI1. Cell Physiol Biochem 37: 387-398, 2015.

58. Chen T, Xu C, Chen J, Ding C, Xu Z, Li C and Zhao J: MicroRNA203 inhibits cellular proliferation and invasion by targeting Bmil in non-small cell lung cancer. Oncol Lett 9: 2639-2646, 2015.

59. Cheng Y, Yang X, Deng X, Zhang X, Li P, Tao J and Lu Q MicroRNA-218 inhibits bladder cancer cell proliferation, migration, and invasion by targeting BMI-1. Tumour Biol 36 : 8015-8023, 2015

60. Wang T, Chen T, Niu H, Li C, Xu C, Li Y, Huang R, Zhao J and Wu S: MicroRNA-218 inhibits the proliferation and metastasis of esophageal squamous cell carcinoma cells by targeting BMI1. Int J Mol Med 36: 93-102, 2015.

61. Xuan H, Xue W, Pan J, Sha J, Dong B and Huang Y: Downregulation of miR-221, -30d, and -15a contributes to pathogenesis of prostate cancer by targeting Bmi-1. Biochemistry (Mosc) 80: 276-283, 2015

62. Liu L, Qiu M, Tan G, Liang Z, Qin Y, Chen L, Chen H and Liu J: miR-200c inhibits invasion, migration and proliferation of bladder cancer cells through down-regulation of BMI-1 and E2F3. J Transl Med 12: 305, 2014.

63. Qi X, Li J, Zhou C, Lv C and Tian M: MicroRNA-320a inhibits cell proliferation, migration and invasion by targeting BMI-1 in nasopharyngeal carcinoma. FEBS Lett 588: 3732-3738, 2014

64. Kahlert UD, Nikkhah G and Maciaczyk J: Epithelial-tomesenchymal(-like) transition as a relevant molecular event in malignant gliomas. Cancer Lett 331: 131-138, 2013.

65. Elias MC, Tozer KR, Silber JR, Mikheeva S, Deng M, Morrison RS, Manning TC, Silbergeld DL, Glackin CA, Reh TA, et al: TWIST is expressed in human gliomas and promotes invasion. Neoplasia 7: 824-837, 2005.

66. Han SP, Kim JH, Han ME, Sim HE, Kim KS, Yoon S, Baek SY, Kim BS and Oh SO: SNAI1 is involved in the proliferation and migration of glioblastoma cells. Cell Mol Neurobiol 31: 489-496, 2011.

67. Mikheeva SA, Mikheev AM, Petit A, Beyer R, Oxford RG, Khorasani L, Maxwell JP, Glackin CA, Wakimoto H, González-Herrero I, et al: TWIST1 promotes invasion through mesenchymal change in human glioblastoma. Mol Cancer 9: 194, 2010.

68. Pang H, Zheng Y, Zhao Y, Xiu X and Wang J: miR-590-3p suppresses cancer cell migration, invasion and epithelialmesenchymal transition in glioblastoma multiforme by targeting ZEB1 and ZEB2. Biochem Biophys Res Commun 468: 739-745, 2015.

69. Li J, Yuan J, Yuan X, Zhao J, Zhang Z, Weng L and Liu J: MicroRNA-200b inhibits the growth and metastasis of glioma cells via targeting ZEB2. Int J Oncol 48: 541-550, 2016.

70. He X, Liu Z, Peng Y and Yu C: MicroRNA-181c inhibits glioblastoma cell invasion, migration and mesenchymal transition by targeting TGF- $\beta$ pathway. Biochem Biophys Res Commun 469: 1041-1048, 2016 